\title{
Interactions between brainstem noradrenergic neurons and the nucleus accumbens shell in modulating memory for emotionally arousing events
}

\author{
Erin C. Kerfoot ${ }^{1,2}$ and Cedric L. Williams ${ }^{1,3}$ \\ ${ }^{1}$ Department of Psychology, Graduate Program in Neuroscience, University of Virginia, Charlottesville, Virginia 22904, USA
}

\begin{abstract}
The nucleus accumbens shell (NAC) receives axons containing dopamine- $\beta$-hydroxylase that originate from brainstem neurons in the nucleus of the solitary tract (NTS). Recent findings show that memory enhancement produced by stimulating NTS neurons after learning may involve interactions with the NAC. However, it is unclear whether these mnemonic effects are mediated by norepinephrine (NE) release from NTS terminals onto NAC neurons. The present studies approached this question by examining the contribution of NAC $\alpha$-noradrenergic receptors in mediating this effect and assessed whether glutamatergic activation of the NTS alters NE concentrations in the NAC. Rats were trained for $6 \mathrm{~d}$ to drink from a water spout located at the end of an inhibitory avoidance chamber. On day 7, a 0.35-mA footshock was initiated once the rat approached the spout and remained active until it escaped into the neutral compartment. Blockade of $\alpha$-noradrenergic receptors in the NAC with phentolamine $(0.5 \mu \mathrm{g} / 0.5 \mu \mathrm{L})$ attenuated memory enhancement produced by glutamatergic ( $50 \mathrm{ng} / 0.5 \mu \mathrm{L})$ infusion on NTS neurons $(P<0.01)$. Experiment 2 used in vivo microdialysis to assess whether glutamate activation of NTS alters NAC NE concentrations. NE levels were unchanged by NTS infusion of phosphate-buffered saline (PBS) or low dose glutamate $(50 \mathrm{ng} / 0.5 \mu \mathrm{L})$ but elevated significantly $(P<0.05)$ by combining the same dose with the footshock $(0.35 \mathrm{~mA}, 2 \mathrm{sec})$ given in Study 1 or infusion of $(100 \mathrm{ng} / 0.5 \mu \mathrm{L})$ glutamate alone. Findings demonstrate that NE released from NTS terminals enhances representations in memory by acting on $\alpha$-noradrenergic receptors within the NAC.
\end{abstract}

The shell division of the nucleus accumbens (NAC) receives highly processed information regarding affective and contextual features of new learning experiences from the amygdala and hippocampus, respectively (Mogenson et al. 1980; Groenewegen et al. 1987; Meredith et al. 1990; Wang et al. 1992; Brog et al. 1993; Petrovich et al. 1996; French and Totterdell 2003). These limbic inputs are complemented by norepinephrine containing axons supplied by the A2 class of noradrenergic neurons housed in the brainstem region of the nucleus of the solitary tract (NTS) (Delfs et al. 1998). Norepinephrine release from A2 NTS neurons play an important role in conveying information regarding experience-induced changes in the physiological state of the organism.

The A2 neurons are activated during times of heightened arousal by the release of glutamate from vagal nerve fibers that ascend from the periphery to the brainstem (Allchin et al. 1994; King and Williams 2009). Highly arousing events increase epinephrine secretion from the adrenals and facilitate binding to $\beta$-adrenergic receptors along the vagus nerve (Lawrence et al. 1995) that in turn, increase impulse flow to brainstem neurons in the NTS (Lawrence et al. 1995; Miyashita and Williams 2006). Epinephrine administration, stimulation of the vagus nerve or direct infusion of glutamate onto A2 NTS neurons are all known to significantly potentiate norepinephrine release within the amygdala and hippocampus (Segal et al. 1991; Liang et al. 1995; Williams et al. 1998; Izumi and Zorumski 1999; Hassert et al. 2004; Miyashita and Williams 2004; Roosevelt et al. 2006).

\footnotetext{
2Present address: Department of Psychology, University of North Carolina, Chapel Hill, NC 27599, USA.

${ }^{3}$ Corresponding author.

E-mail clw3b@virginia.edu; fax (434) 982-4785.

Article is online at http://www.learnmem.org/cgi/doi/10.1101/Im.2108911.
}

Elevated concentrations of norepinephrine in these limbic areas play a key role in facilitating memory for responses acquired under a wide range of emotionally arousing learning conditions (Liang et al. 1995; Bevilaqua et al. 1997; Ferry et al. 1999; Hatfield and McGaugh 1999; Roozendaal et al. 2008; KhakpourTaleghani et al. 2009; Scullion et al. 2009; Radwanska et al. 2010).

However, recent findings indicate that these mnemonic effects may emerge from similar actions of the NTS on neurons restricted within the shell division of the NAC (Kerfoot et al. 2008). For example, electrophysiological findings validate a functional relationship between the viscera, NTS and the accumbens since increasing discharge along ascending vagal fibers that terminate within the NTS, potentiates neuronal firing in the NAC (Mehendale et al. 2004). Similar changes in the firing properties of accumbens neurons are observed in response to activating NTS neurons with microinfusions of the excitatory amino acid glutamate or by applying current stimulation to the NTS (Kirouac and Ciriello 1997). Although this subdivision of the accumbens receives innervations from both the locus coeruleus and NTS, only axons originating from A2 cells contain the norepinephrine precursor, dopamine- $\beta$-hydroxylase (Delfs et al. 1998). Despite these anatomical connections, evidence demonstrating a functional relationship between A2 noradrenergic neurons and their capacity to activate the NAC through norepinephrine release following emotional learning conditions is not currently available.

Findings from a recent behavioral study revealed that memory improvement produced by exciting NTS neurons with glutamate is completely reversed by chemical inactivation of the NAC with the long acting anesthetic bupivacaine (Kerfoot et al. 2008). These findings suggests that synaptic plasticity within the NAC plays a key role in mediating the improvement in cognitive functioning produced by exciting noradrenergeric neurons in the NTS following emotional learning. They are limited, however, 
in identifying the mechanism involved in mediating these changes in cognitive processing. Since the presence of dopamine- $\beta$-hydroxylase in the shell originates exclusively from NTS axons innervating this region (Delfs et al. 1998), it may be that adrenoceptors in the NAC play a pivotal role in improving memory for new learning experiences following NTS activation.

It is still not clear, however, whether the enhancement in mnemonic processes following NTS activation is influenced by noradrenergic transmission in the NAC. Therefore, the current study determined whether stimulation of the NTS with glutamate modulates activity in the NAC through influences on $\alpha$-adrenergic receptors within this nucleus. A second objective of this study was to validate with in vivo microdialysis and high-performance liquid chromatography (HPLC) if the consequences of this treatment on NTS neurons affects norepinephrine output in the NAC of behaving animals. The combined studies are expected to provide behavioral and neurochemical evidence that interactions between the NTS and NAC following emotional learning conditions involve noradrenergic influences from the brainstem on shell $\alpha$-noradrenergic receptors.

\section{Results}

\section{Experiment 1: Phase 1 of retention testing}

Rats were trained for $6 \mathrm{~d}$ to drink water from a spout located at the end of the dark compartment of an inhibitory avoidance chamber. On day 7, a $0.35-\mathrm{mA}$ footshock was initiated once the rat approached the spout and remained active until it escaped into the neutral compartment. One minute following the shock and escape, rats received intraaccumbens microinjections of either phosphate-buffered saline (PBS) or the $\alpha$-adrenoceptor antagonist, phentolamine (Fig. 1A,B). Following accumbens injections, microinfusions of either PBS or glutamate $(50 \mathrm{ng} / 0.5 \mu \mathrm{L})$ were delivered into the NTS (Fig. 1C,D). Rats were returned to their home cage for $24 \mathrm{~h}$ before the first phase of retention testing.

\section{Experiment 1: Phase 2 of retention testing}

\section{Contextual memory: Time spent avoiding the shock/dark compartment}

Immediately after Phase 1, each animal was placed in the well-lit neutral compartment for $30 \mathrm{sec}$ to begin Phase 2 of the retention test. After this delay, the metal door separating the neutral-illuminated from the shock compartment was lowered and the latency to enter the dark compartment was recorded (Fig. 2B). A two-way ANOVA indicated a significant interaction between NTS and NAC treatments for the latency to enter the shock compartment, $F_{(1,30)}=9.14, P<0.01$. As shown in Figure 3, animals given intra-NAC PBS followed by glutamate in the NTS spent significantly more time in the neutral compartment before entering the context where footshock was administered $24 \mathrm{~h}$ previously $(P<0.01$ compared with all other treatment groups). Blocking $\alpha$-noradrenergic receptors in the NAC with phentolamine attenuated the enhancement in memory produced by intra-NTS glutamate infusion. The time spent in the neutral compartment for this group (Glut-Phentolamine) was not different from that of PBS controls but was significantly lower than that of the GlutPBS group $(P<0.01)$.

During Phase 2, the door separating the neutral and shock compartment remained open permitting the subjects to move freely between both compartments. The latency to initiate licking upon entry into the shock compartment and time spent drinking was recorded during this second period of retention testing. These measures assess learning induced fear of the context associated with footshock delivery in addition to the strength of memory for the last response emitted before experiencing the shock (i.e., licking). A two-way ANOVA revealed a significant interaction between NTS and NAC injections, $F_{(1,30)}=6.32, P<0.05$ (Fig. 4 A) with the Glutamate/PBS group displaying significantly longer latencies to initiate drinking relative to PBS/PBS controls $(P<$ 0.01 ) or animals given phentolamine in the NAC and PBS in the NTS $(P<0.01)$. However, blocking $\alpha$-adrenoreceptors in the NAC prevented this effect. Subjects given phentolamine into
Latency to emit an active avoidance response or drink from the spout

During Phase 1 of retention testing, each animal was placed in the dark compartment and the latency to lick the water spout or enter the safe/neutral compartment was measured until the end of the 60-sec test (Fig. 2A). A two-way analysis of variance (ANOVA) revealed no significant interaction between treatment groups on the mean seconds to enter the neutral compartment, $F_{(1,30)}=0.12, P=$ ns (PBS/PBS $46.5 \pm 4.2$, phentolamine/ PBS $42.0 \pm 5.5, \quad \mathrm{PBS} /$ glutamate $45.0 \pm$ 7.6, phentolamine/glutamate $45.0 \pm 8.3$ ) or to initiate drinking from the spout, $F_{(1,30)}=3.52, \quad P=$ ns (PBS/PBS 53.1 \pm 7.0, phentolamine/PBS $56.7 \pm 2.6$, PBS/ glutamate $60.0 \pm 0.0$, phentolamine/ glutamate $46.7 \pm 6.6$ ). The Phase 1 test established that the surprise shock given during training produced adequate learning in both control and experimental groups. Phase 2 testing evaluated treatment induced differences in the strength of this memory and the potential contribution of NAC $\alpha$-receptors in mediating these effects.
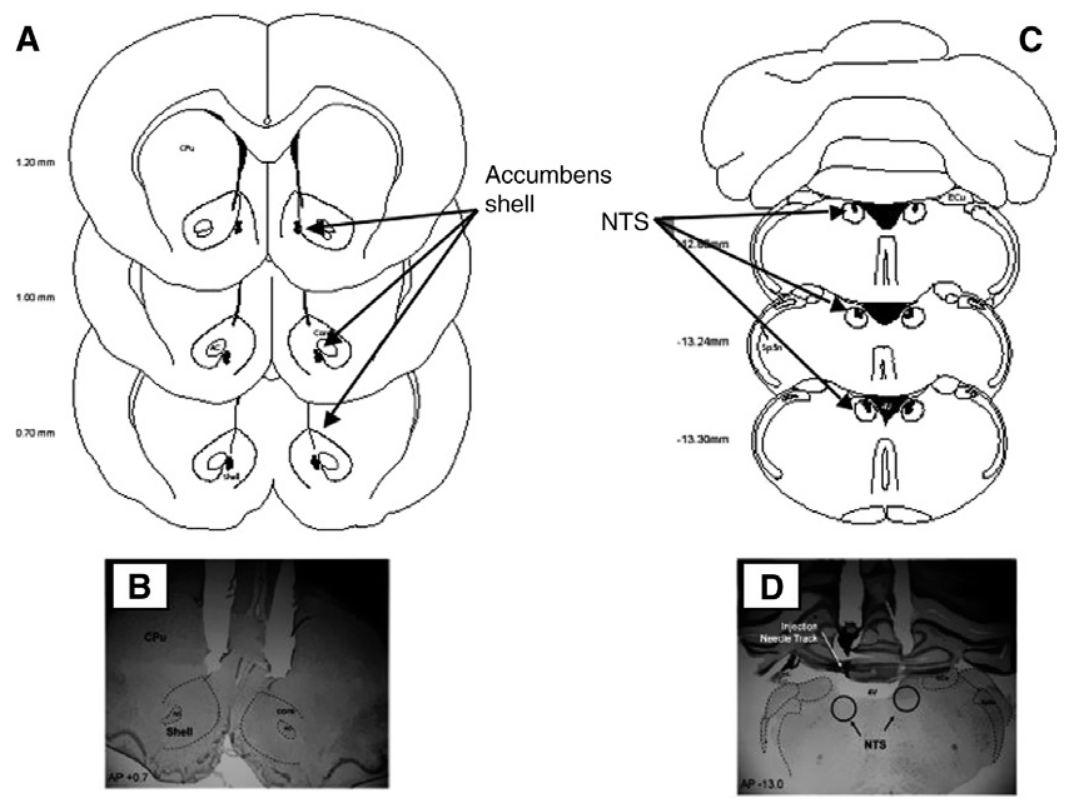

Figure 1. Diagram of injection needle tip placement in the NAC shell $(A)$ and NTS (C) of animals trained and tested in Experiment 1. $B$ and $D$ contain representative photomicrographs of brain sections and the location of injection cannulae above the NAC shell $(B)$ and NTS $(D)$. (4V) Fourth ventrical; (AC) anterior commissure; (core) nucleus accumbens core; (CPu) caudate putamen; (ECu) ext cuneate nucleus; (shell) nucleus accumbens shell; and (Sp5n) spinal trigeminal nucleus. 
A Responses Recorded in Phase 1 of the Retention Test:

1. Latency to escape into the neutral compartment

2. Latency to first lick the spout

3. Amount of time spent drinking from the spout
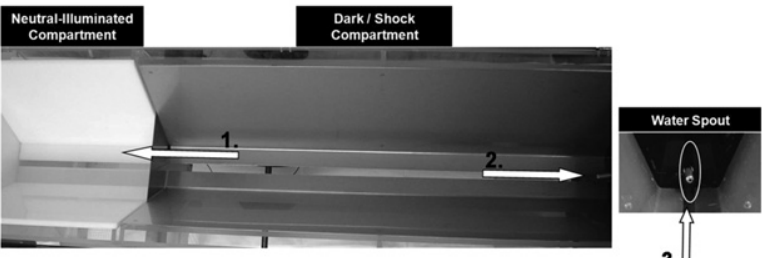

3.

B

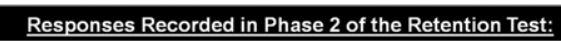

1. Time spent avoiding the dark compartment

2. Latency to enter the dark compartment

3. Latency to first lick the spout

4. Amount of time spent drinking
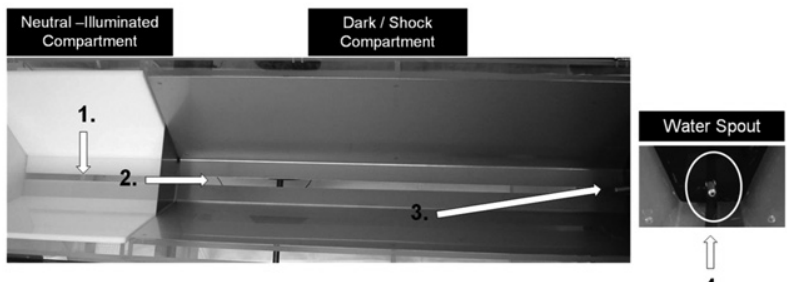

4.

Figure 2. Overhead view of the inhibitory avoidance apparatus and training procedure for Experiment 1. $(A)$ During Phase 1 of retention testing, subjects were placed in the dark compartment facing the sliding door and the latency to either (1) escape into the neutral compartment or (2) lick the spout at the end of the dark compartment was recorded. The total amount of time each animal spent drinking during the 60 -sec test in Phase 1 was also assessed (3). (B) During Phase 2, subjects were placed in the neutral compartment and the following behaviors were recorded: (1) time spent avoiding the dark compartment, (2) latency to enter the shock compartment, (3) percentage of animals to enter the dark compartment, (4) time required to initiate contact and lick from the waterspout, and (5) total time spent drinking from the spout once initial contact was made.

the shell before intra-NTS infusion of glutamate (phentolamine/ glutamate) exhibited significantly shorter latencies to drink from the water spout $(P<0.01)$ than those given the same dose of glutamate and the control PBS infusion into the NAC.

\section{Duration of drinking}

The amount of time each animal spent drinking after initial contact with the water spout served as an additional measure of retention for the response emitted immediately before the delivery of footshock. As shown in Figure 4B, a two-way ANOVA revealed significant differences between treatment groups in the mean time spent drinking, $F_{(1,30)}=1.95, P<0.05$. Animals given PBS/ glutamate spent significantly less time drinking from the spout relative to PBS/PBS controls $(P<0.01)$ or the phentolamine/PBS group $(P<0.01)$. Without $\alpha$-adrenoceptor functioning, animals in the phentolamine/glutamate group did not display the high level of avoidance behavior observed in the PBS/glutamate group $(P<0.01)$.

\section{Experiment 2}

\section{Consequences of NTS activation on accumbens norepinephrine release}

The primary objectives of Experiment 2 were to: (1) directly assess if the combined treatments that facilitated memory in
Experiment 1 (i.e., mild footshock and post-training infusion of a low 50-ng dose of glutamate) affects norepinephrine release in the NAC, and (2) determine if these changes can be simulated in the absence of footshock by increasing the level of NTS neuronal activation with a higher 100-ng dose infusion into this structure. The location of microdialysis or injection cannulae placements in the NAC and NTS, respectively, are displayed in Figure 5, A and B. To achieve these objectives, norepinephrine samples were collected with in vivo microdialysis from the NAC at 20 min intervals (Fig. 6). PBS was infused into the NTS of each of the three treatment groups at the conclusion of the 60 -min period of baseline collection as a control to ensure that microinfusions into this structure alone, were not sufficient to affect norepinephrine output in the NAC. Two hours later, separate groups of rats received intra-NTS infusions of either $50 \mathrm{ng} / 0.5 \mu \mathrm{L}$ or $100 \mathrm{ng} / 0.5 \mu \mathrm{L}$ of l-glutamic acid. The larger dose of glutamate was selected to approximate the level of glutamate present in the NTS in response to the combined treatment of footshock $(0.35 \mathrm{~mA}, 2 \mathrm{sec})$, and glutamate $(50 \mathrm{ng})$ that produced a significant improvement in memory in Experiment 1 and enhanced retention under emotionally arousing learning conditions in previous studies (Miyashita and Williams 2002; Kerfoot et al. 2008). As an additional measure, a third group received the identical experimental treatments (50 ng of glutamate in the NTS along with a 0.35-mA footshock) that facilitated in memory in the first study. As shown in Figure 6, one-way repeated-measures ANOVA evaluated overall changes in NAC norepinephrine concentrations relative to baseline values across the different treatment periods. This analysis indicated a significant overall effect of time, $F_{(2,12)}=13.0, P<$ 0.01 . Post hoc Fisher's tests comparing the mean percentage of change in accumbens norepinephrine concentrations from baseline values relative to those after infusion of PBS into the NTS indicated no significant increase after this treatment $(12 \%$ decrease from baseline, $P=0.21$ ).

Intra-NTS infusions of the low dose $(50 \mathrm{ng})$ of glutamate at time point $180 \mathrm{~min}$ produced no appreciable changes in norepinephrine concentrations (i.e., PBS/GLUT $50 \mathrm{ng}$; open squares). Infusion of the same dose in combination with the low intensity $(0.35 \mathrm{~mA}), 2$-sec footshock used during behavioral training in Experiment 1 produced a significant $217 \%$ increase in

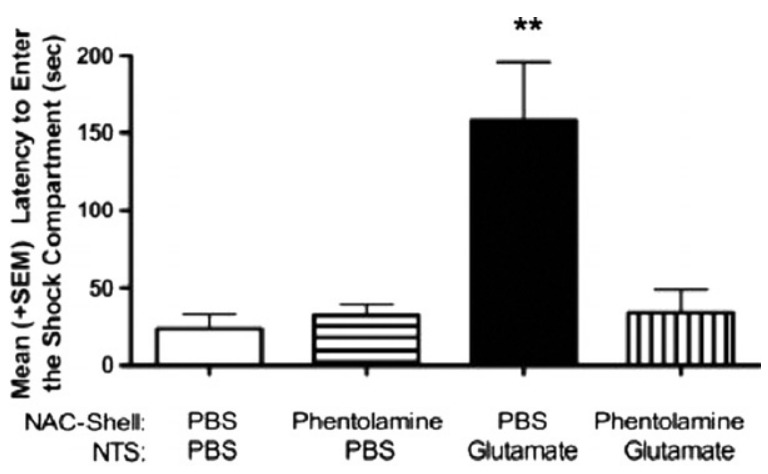

Figure 3. Mean ( $+\mathrm{SE}$ ) latency to enter the dark compartment in Phase 2 retention testing. Animals in the PBS/GLUT (glutamate; $50 \mathrm{ng} / 0.5 \mu \mathrm{L}$ ) group spent significantly more time in the neutral compartment before entering the context where footshock was administered $24 \mathrm{~h}$ previously $(P<0.01$ compared with all other treatment groups). Blocking $\alpha$-noradrenergic receptors in the NAC with phentolamine $(0.5 \mu \mathrm{g} / 0.5 \mu \mathrm{L})$ attenuated the enhancement in memory produced by intra-NTS glutamate infusion (glutamate; $50 \mathrm{ng} / 0.5 \mu \mathrm{L}$ ). The time spent in the neutral compartment for this group (Glut-Phentolamine) was not different from that of PBS controls but was significantly lower than that of the GlutPBS group. ${ }^{* *} P<0.01$. 

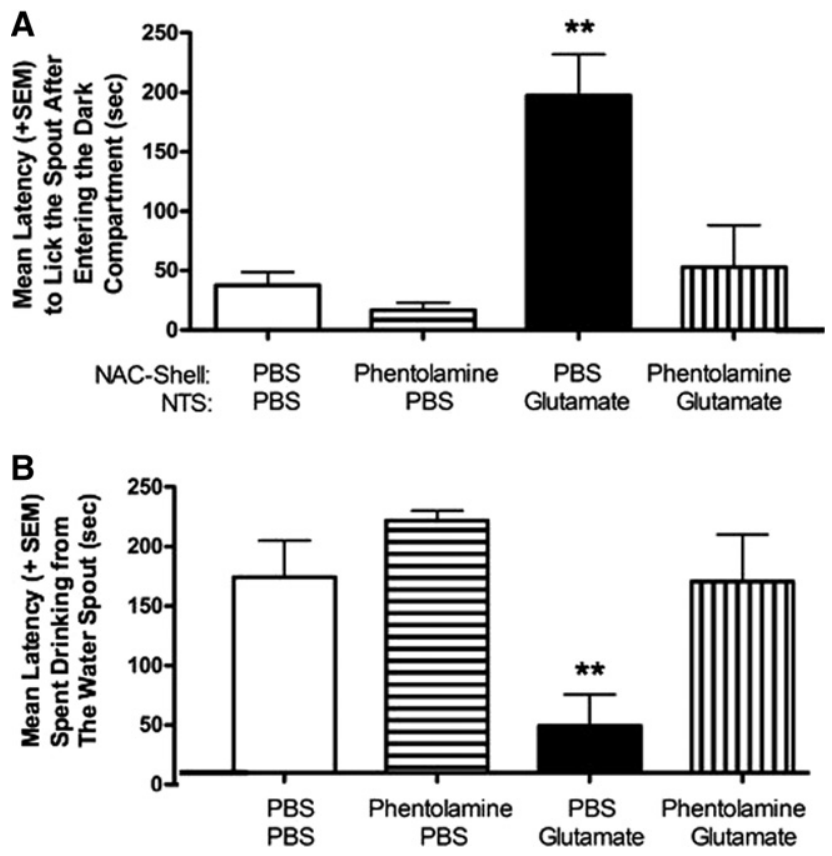

Figure 4. $(A)$ Mean $(+\mathrm{SE})$ latency to lick the spout after entering the shock compartment in Phase 2 retention testing. This measure represents the memory for the last action emitted prior to delivery of the arousing footshock. Activation of NTS neurons with glutamate (PBS/GLUT; glutamate $50 \mathrm{ng} / 0.5 \mu \mathrm{L}$ ) improved retention as subjects in this group took significantly longer $(P<0.01)$ to lick the water spout. Antagonizing $\alpha$ noradrenergic receptors in the NAC with phentolamine (i.e., Phentolamine/GLUT; phentolamine $0.5 \mu \mathrm{g} / 0.5 \mu \mathrm{L}$ ) attenuated this effect. (B) Mean (+SE) amount of time spent drinking from the water spout during Phase 2 of retention testing. Post-training activation of glutamate receptors in the NTS (PBS/GLUT) facilitated memory for footshock training, and subjects in this group required a significantly longer period of time to drink from the water spout during Phase 2 of the retention test $(P<0.01)$. Again, animals treated with the same dose of glutamate in the NTS, but phentolamine in the NAC, look similar to controls and drink for $\sim 150 \mathrm{sec}$ of a 300 -sec test. ${ }^{* *} P<0.01$.

norepinephrine output relative to Baseline 2 values $(P<0.01$, SHOCK/GLUT $50 \mathrm{ng}$; open diamonds). Intra-NTS infusion of $100 \mathrm{ng}$ of glutamate (PBS/Glut $100 \mathrm{ng}$ ) without footshock also produced a significant increase in NAC noradrenergic output (49\% increase from Baseline 2; $P<0.05$, closed squares). Elevation in norepinephrine levels for the PBS/GLUT 100-ng group persisted throughout minutes 200 (108\%), 220 (154\%), 240 (188\%), 260 (201\%), 280 (219\%), 300 (223\%), and 320 (244\%). A similar increase in norepinephrine output was seen in the SHOCK/GLUT 50-ng group at minutes 200 (116\%), 220 (123\%), $240(113 \%), 260(125 \%), 280(155 \%), 300(152 \%)$, and 320 $(155 \%)$. These findings are consistent with those reported by McKittrick and Abercrombie (2007) showing that norepinephrine in the NAC remains elevated for as long as $240 \mathrm{~min}$ in response to peripheral administration of d-amphetamine.

Factorial ANOVAs were used to assess individual differences in NAC norepinephrine output resulting from the separate treatment conditions. Overall ANOVAs comparing changes in norepinephrine output between the PBS/GLUT 50-ng and SHOCK/ GLUT 50-ng groups revealed a significant effect, $F_{(1,12)}=5.8$, $P<0.01$. Post hoc comparisons demonstrated that norepinephrine concentrations in the SHOCK/GLUT 50-ng group were elevated significantly higher than those sampled from the NAC of the PBS/GLUT $50 \mathrm{ng}$ at time points (min 180-320, $P<0.05$ ). Overall ANOVAs comparing changes in norepinephrine output between the PBS/GLUT 50-ng and PBS/GLUT 100-ng groups revealed a significant differences, $F_{(1,12)}=10.9, P<0.01$. As with the previous analyses, post hoc comparisons of changes in norepinephrine output between the PBS/GLUT 50-ng and PBS/ GLUT 100-ng groups revealed that levels of the transmitter were significantly higher in the PBS/GLUT 100-ng group at time points (min 180-320, $P<0.05$ ).

\section{Discussion}

A great deal of attention is devoted to understanding the contribution of the NAC in forming associations between rewarding stimuli and increases in motivated behaviors. The functional significance of the NAC is being expanded to include roles in processing memory for learning conditions involving emotionally arousing stimuli. Recent reports demonstrated that memory improvement induced by stimulating NTS brainstem neurons involves interactions with the NAC, while direct stimulation of $\alpha$-noradrenergic receptors within this nucleus produce similar effects on cognitive processing (Kerfoot et al. 2008). These results indicate that information conveyed by NTS neurons in the form of visceral and hormonal changes, indicative of heightened states of arousal, modulate NAC activity during memory storage.

NTS neurons influence noradrenergic output in key structures that utilize this transmitter to regulate memory such as the amygdala or hippocampus (Clayton and Williams 2000; Williams et al. 2000; Miyashita and Williams 2002, 2004). Yet, few if any studies have examined whether the circuitry between these brainstem neurons and the NAC contributes to this process. In light of this shortcoming, the current study used both behavioral and neurochemical approaches to assess whether excitation of noradrenergic NTS neurons and the resulting facilitation in
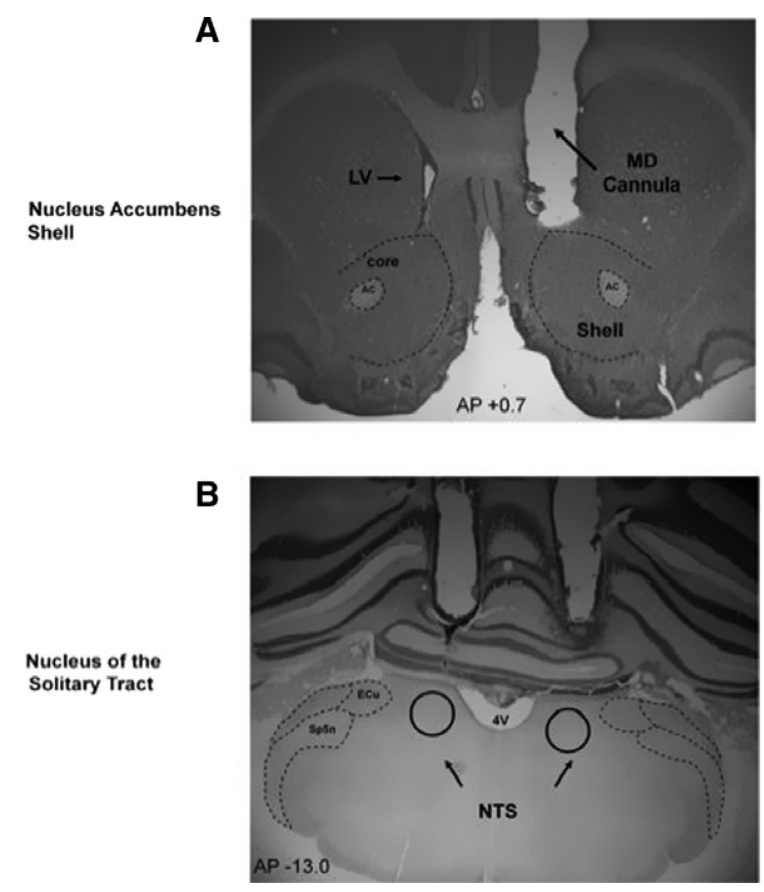

Figure 5. Location of microdialysis cannula placements in the NAC and needle tip placements $(A)$ in the NTSoverlaid onto a representative photomicrograph from animals trained and tested in Experiment 2 (B). (4V) fourth ventrical; (AC) anterior commissure; (core) nucleus accumbens core; (ECu) ext cuneate nucleus; (LV) lateral ventricle; (MD cannula) unilateral microdialysis cannula (counterbalanced for side); (shell) nucleus NAC; and (Sp5n) spinal trigeminal nucleus. 


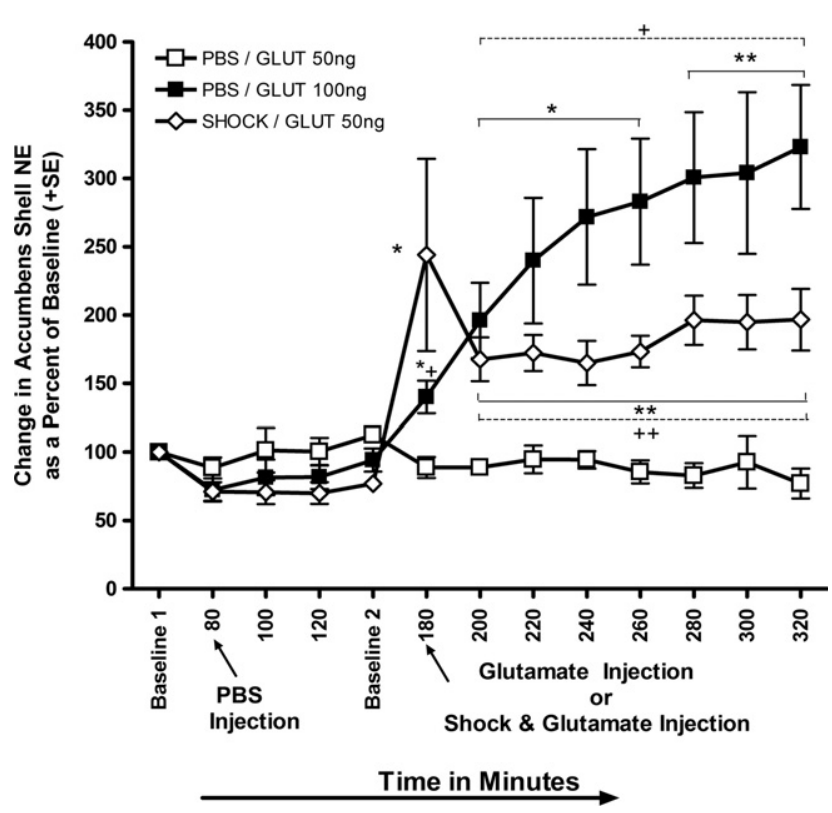

Figure 6. Mean $( \pm S E)$ change in NAC norepinephrine levels as a percent of baseline. NTS infusions of PBS immediately following $60 \mathrm{~min}$ of baseline measurements or a low dose of glutamate $(50 \mathrm{ng})$ infused at minute 180, produced no appreciable fluctuations in norepinephrine levels in the NAC. However, at minute 180 similar infusions of $50 \mathrm{ng}$ glutamate into the NTS in combination with a mild footshock caused a $167 \%$ increase in extracellular concentrations of norepinephrine collected from the accumbens. This effect could be simulated in animals given intra-NTS infusions of a higher, $100 \mathrm{ng}$, dose of glutamate alone. Repeatedmeasures analysis revealed a significant enhancement in norepinephrine release in both the SHOCK/GLUT 50-ng and PBS/GLUT 100-ng groups. This enhancement persisted in both groups from the time point where the glutamate and/or shock was administered throughout the end of the experiment $\left({ }^{*} P<0.05,{ }^{*} P<0.01\right)$. Factorial analysis revealed that norepinephrine levels were significantly elevated from minute 180-320 in the PBS/GLUT 100-ng group compared with the PBS/GLUT 50-ng group. Norepinephrine levels in the SHOCK/GLUT 50-ng group were significantly augmented from PBS/GLUT 50-ng at minute 200-320 $\left({ }^{+} P<\right.$ $0.05,++p<0.01)$.

memory is mediated by the release of norepinephrine on $\alpha$-noradrenergic receptors within the shell.

Findings from the first study were consistent with previous reports showing that intra-NTS infusion of glutamate facilitates memory for emotionally arousing learning experiences (Miyashita and Williams 2002; Kerfoot et al. 2008). The beneficial effects of activating NTS neurons were evident by enhanced retention performance in a number of separate measures for animals in the PBS/glutamate group. Subjects given intra-NTS infusion of glutamate distinguished themselves from all other groups with delayed latencies to either enter the dark section of the chamber where footshock was given during training (Fig. 3) or to drink from the spout located in this section of the apparatus during retention testing (Fig. 4A). These aspects of responding considered together with the finding that the PBS/glutamate groups spent significantly less time drinking at the spout (Fig. 4B) suggest that post-training excitation of the NTS facilitates processes involved in storing affective and contextual attributes of the environment in which the emotionally arousing footshock was given $24 \mathrm{~h}$ earlier.

Experiment 1 also revealed possible interactions between the NTS and NAC, since blocking $\alpha$-noradrenergic receptors in the shell with phentolamine (Figs. 3, 4) attenuated the beneficial effects of exciting the NTS on retention. Animals in the
Phentolamine/Glutamate group entered the context where footshock was experienced $24 \mathrm{~h}$ previously, much sooner than the $\mathrm{PBS} /$ Glutamate group and displayed faster latencies to initiate drinking from the water spout. Despite the memory enhancing treatment of glutamate in the NTS, animals without proper $\alpha$-noradrenergic receptor functioning (Phentolamine/Glutamate group) performed more like control animals. These results illustrate a functional relationship between norepinephrine from the NTS acting on $\alpha$-noradrenergic receptors in the NAC to enhance memory for arousing events. The current finding is consistent with recent reports that a reduction in norepinephrine levels in the NAC impairs spatial performance in a conditioned place preference task (Kitanaka et al. 2010) and conditioned aversive learning in an elevated plus maze task (Carvalho et al. 2010). The current study also extends these finding by demonstrating that noradrenergic transmission from the NTS to the NAC is mediated by selective actions on $\alpha$-noradrenergic receptors in the shell.

Findings from Experiment 2 revealed that activation of NTS A2 neurons with glutamate produces robust and long-lasting increases in norepinephrine output in the NAC. Specifically, in vivo microdialysis results showed that the low-dose $(50 \mathrm{ng})$ infusion of glutamate in the NTS produced no appreciable fluctuations in norepinephrine levels in the NAC. In contrast, norepinephrine levels were significantly potentiated when this dose was combined with a single arousing footshock identical to that used during behavioral training in Experiment 1 (Fig. 6). This is consistent with findings from Miyashita and Williams (2002) showing that footshock and $50 \mathrm{ng}$ of glutamate in the NTS potentiates norepinephrine release in the basolateral amygdala. Additionally, this finding demonstrates that the smaller concentration of glutamate alone (similar to PBS controls) may not provide a sufficient level of activation within the brainstem to impact the release of norepinephrine from NTS terminals innervating the NAC.

The elevated levels of norepinephrine sampled from animals in the SHOCK/GLUT 50-ng group was also simulated by infusing a higher dose of glutamate (100 ng) in the absence of the emotionally arousing footshock. The magnitude of activating NTS neurons was revealed by the finding that norepinephrine concentrations in the NAC remained elevated for at least $2 \mathrm{~h}$ and $20 \mathrm{~min}$ in groups given the high dose of glutamate or the low dose with a footshock. Norepinephrine concentrations escalated to $229 \%$ above Baseline 2 for the PBS/GLUT 100 ng group and 119\% for the SHOCK/GLUT 50-ng group. Norepinephrine levels may not have remained as high compared with the initial collection following footshock and injection because animals are removed from the context where the footshock occurred.

\section{Norepinephrine in the NAC}

Many studies examining neurotransmitter activity within the accumbens focused primarily on the functions of dopamine within this structure. Although a number of early immunohistochemical experiments reported the presence of norepinephrine in the NAC, later investigations delineating between core and shell found norepinephrine primarily in the caudal shell and few, if any, in the core (Berridge et al. 1997; Schroeter et al. 2000). Using fast-scan cyclic voltammetry in combination with a norepinephrine autoreceptor blocker and transporter blocker, Park et al. (2010) demonstrated that norepinephrine signaling was restricted to the caudal shell, whereas the rostral shell was selective for dopamine signaling.

Although the locus coeruleus and NTS are known to project to the caudal NAC (Brog et al. 1993), only projections from NTS neurons contain norepinephrine (Delfs et al. 1998). Additional studies suggest that noradrenergic innervation of the NAC derives from the NTS and not the LC. For example, Holdefer and Jensen 
(1987) demonstrated that systemic injection of amphetamine does not increase discharge of LC neurons, but actually suppresses LC activity. Given findings showing d-amphetamine potentiates norepinephrine output in the NAC combined with the finding showing that d-amphetamine suppresses LC activity (Holdefer and Jensen 1987), it is apparent that treatments that affect physiological arousal must therefore increase norepinephrine output in the NAC through the only other noradrenergic pathway innervating this structure, the NTS.

The current study provides additional evidence of functional connections between noradrenergic fibers arising in the NTS and the presence of norepinephrine in the caudal region on the NAC. These results are in agreement with data showing that neuronal firing in the NAC is elevated following either electrical or glutamatergic activation of neurons in the NTS (Kirouac and Ciriello 1997). The current results extend these data and suggest that increased NAC firing in response to NTS activation may be due to a long-lasting release of norepinephrine from NTS terminals. Consistent with this view, other treatments that improve memory through influences on noradrenergic transmission such as d-amphetamine also produce profound effects on norepinephrine output in the NAC that persist for up to $4 \mathrm{~h}$ following administration (McKittrick and Abercrombie 2007). In addition to norepinephrine, other findings demonstrate that direct infusion of dopamine into the NAC shell but not core also facilitate memory (LaLumiere et al. 2005). Moreover, this effect requires concomitant activation of dopamine receptors within the basolateral amygdala since anatagonizing these receptors with the general antagonist cis-Flupenthixol attenuates the memory improvement produced by dopamine excitation of the NAC (LaLumiere et al. 2005).

\section{Norepinephrine actions on a-noradrenergic receptors in the NAC}

The NAC contains both $\alpha$ - and $\beta$-adrenergic receptors (Rainbow et al. 1984; Unnerstall et al. 1984). Although both receptor subtypes are present, only $\alpha$-receptors are known to influence norepinephrine-mediated transmission in the shell (Nicola et al. 1996; Nicola and Malenka 1998; Kombian et al. 2006). This finding is important in validating a distinction between these receptor types since other studies report that norepinephrine released from A1, A2, and A5 neurons act primarily on $\alpha$-receptors, whereas $\mathrm{A} 4$ and $\mathrm{A} 6$ cell groups are more effective in activating $\beta$-noradrenergic receptors (Cools et al. 1987). This distinction is further characterized by results indicating that $\beta$-noradrenergic receptors in the shell play an important role in regulating dopamine release (Reisine et al. 1982; Nurse et al. 1984). Specifically, $\beta$ - rather than $\alpha$-noradrenergic receptors activate $\alpha$-methyl-p-tyrosine-sensitive, reserpine-resistant pools in the NAC (Tuinstra and Cools 2000). Moreover, recent evidence demonstrates that blocking $\beta$-noradrenergic receptors in the shell with propranolol was not effective in influencing associative memory in a conditioned place preference task (Fricks-Gleason and Marshall 2008).

Although suppression of $\beta$-noradrenergic receptors does not influence learning under these behavioral conditions, stimulation of $\alpha$-noradrenergic receptors with intraaccumbens infusion of phenlyephrine significantly improved long-term retention in a reward reduction task (Kerfoot et al. 2008). These findings illustrate the significance of $\alpha$-noradrenergic activation in influencing synaptic changes within the NAC that are necessary at the time of encoding to facilitate long-term memory.

\section{Conclusion}

Along with noradrenergic innervation from A2 NTS neurons in the brainstem, the NAC also receives projections from both the hippocampus (Groenewegen et al. 1987; Meredith et al. 1990; French and Totterdell 2003) and basolateral amygdala (Mogenson et al. 1980; Petrovich et al. 1996; French and Totterdell 2003). These inputs may contribute to the capacity of the NAC to process declarative forms of information and store the motivational valence of stimuli into memory. Interestingly, projections from the basolateral amygdala and hippocampus converge monosynaptically onto projection neurons within the caudomedial part of the NAC (French and Totterdell 2003). This area also receives noradrenergic terminals from the NTS (Delfs et al. 1998). This arrangement of synaptic inputs provides the foundation for understanding how information from the NTS regarding physiological arousal may ultimately modulate the processing of emotional and contextual attributes of newly learned experiences within the NAC.

\section{Materials and Methods}

\section{Subjects}

Fifty-one male Sprague-Dawley rats (275-300 g) obtained from Charles River Laboratories (Wilmington, MA) were used in Experiment $1(n=37)$ and Experiment $2(n=14)$. The rats were individually housed in polypropylene cages with corncob bedding and maintained on a standard 12:12-h light-dark cycle with lights on at 7:00 a.m. Food and water were available ad libitum during the 7-d adaptation period to the vivarium.

\section{Surgery}

Each rat received an injection of atropine sulfate $(0.1 \mathrm{mg} / \mathrm{kg}$ i.p., American Pharmaceutical Partners, Inc.) and was then anesthetized with sodium pentobarbital $(50 \mathrm{mg} / \mathrm{kg}$, i.p., Abbot Laboratories). For Experiment 1, a midline scalp incision was made and bilateral $15 \mathrm{~mm}$-long extra thin-wall stainless steel guide cannula (25 gauge, Small Parts) were implanted $2 \mathrm{~mm}$ above the NAC (AP $+0.7, \mathrm{ML}+1.0$ from bregma, DV -5.4 from skull surface) and NTS (AP $-13.3, \mathrm{ML}+1.0$ from bregma, $\mathrm{DV}-5.6$ from skull surface). In Experiment 2, a unilateral microdialysis cannula was implanted above the NAC and bilateral drug cannulae were secured above the NTS. All coordinates were identical to those used in Experiment 1 and were adapted from the atlas of Paxinos and Watson (1986). Unilateral NAC microdialysis cannula were counterbalanced for side such that roughly equal numbers of animals were implanted with cannula in the right and left hemispheres. The cannula and jeweler's screws were affixed to the skull with dental cement and the scalp closed with sutures. Penicillin $(0.1 \mathrm{~mL}$ i.m., Fort Dodge Animal Health) was administered immediately after surgery along with the analgesic, buprenex $(0.05 \mathrm{~mL}$ s.c., Hospira, Inc.). The rats remained in a temperature-controlled chamber for at least $1 \mathrm{~h}$ following surgery and given $7 \mathrm{~d}$ to recover before initiating water deprivation or behavioral training.

\section{Microinjection procedure}

Each rat was restrained by hand, the stylets removed, and $17-\mathrm{mm}$, 30 -gauge injection needles were inserted bilaterally into the NAC first, and followed $\sim 2$ min later by bilateral injections into the NTS guide cannula. The tip of the injection needles extended $2 \mathrm{~mm}$ beyond the base of the guide cannulae. The needles were connected to $10-\mu \mathrm{L}$ Hamilton syringes by PE-20 (polyethylene) tubing. An automated syringe pump (Sage-Orion) delivered the respective drugs for a total volume of $0.5 \mathrm{~mL}$ over $60 \mathrm{sec}$. The injection needles were left in place for an additional $60 \mathrm{sec}$ following infusions to ensure complete delivery of the drugs and the stylets were then reinserted into the cannulae. In the second study, microdialysis probes were lowered into the accumbens guide cannulae before the start of the experiment and bathed with artificial cerebrospinal fluid. Procedures described above were used for microinjections of PBS or glutamate into the NTS (specific time periods of each injection is listed in the Materials and Methods section). 


\section{Experiment 1: Water-motivated inhibitory avoidance task}

\section{Apparatus}

A trough-shaped, two-compartment rectangular apparatus $(91 \mathrm{~cm}$ long, $21 \mathrm{~cm}$ wide at the top, and $6.4 \mathrm{~cm}$ wide at the bottom) with a hinged lid was used to train the rats in a water-motivated inhibitory avoidance task. A sliding metal door $(14.5 \mathrm{~cm})$ separated a neutral and dark compartment. The neutral compartment was constructed of white opaque Plexiglas ( $31 \mathrm{~cm}$ long) and brightly illuminated by a 60 -watt light located directly above the compartment. The dark compartment was constructed of stainless steel plates ( $60 \mathrm{~cm}$ long). A curved stainless steel water spout connected to a 30-cc plastic syringe containing water was placed $1 \mathrm{~cm}$ above the floor at the end of the dark compartment.

\section{Pretraining manipulations}

One week after surgery, rats were placed on a water maintenance schedule with daily access to water during behavioral training and for $20 \mathrm{~min}$ in their home cage. Body weights were monitored daily to ensure that they remained within $10 \%$ of their ad lib feeding weights throughout the experiment.

\section{Training}

Animals were habituated during a 5-min period of exploration with the opportunity to cross between the white and dark compartments of the inhibitory avoidance apparatus. During training, each rat was placed in the dark compartment facing the retractable door that separated the dark from the illuminated compartment. The metal door was lowered to two-thirds of its length (i.e., creating a 4-cm hurdle), a timer was started and the (1) latency to begin drinking, (2) total amount of time spent drinking, (3) total amount of time spent in the dark compartment, and (4) total amount of time spent in the white illuminated compartment was recorded. Each rat received one training trial lasting 120 sec on each of 6 consecutive days.

On day 7 (i.e., experimental day), each rat was placed in the dark compartment as before; however, a 0.35 -mA electrical footshock was administered as soon as the rat initiated the first lick toward the water spout. The shock remained on until the animal escaped from the dark compartment by crossing over the 4-cm-high hurdle into the illuminated neutral compartment. Each animal was retained in the neutral compartment for $30 \mathrm{sec}$ with the door two-thirds open; the door was then raised and the animals remained in the neutral compartment for an additional $30 \mathrm{sec}$. During this time, they were given the opportunity to cross between the white and dark compartment (shown in Fig. 2A,B) and to explore the drinking spout. Hence, the animals were allowed $60 \mathrm{sec}$ to learn that the white illuminated compartment was safe relative to the dark compartment where footshock was just experienced. Each animal was then removed from the apparatus and given an intraaccumbens infusion of PBS or the $\alpha$-adrenoceptor antagonist, phentolamine $(0.5 \mathrm{mg} / 0.5 \mathrm{~mL})$. The accumbens injections were then followed by bilateral intra-NTS infusion of either PBS or the dose of l-glutamic acid $(50 \mathrm{ng} / 0.5 \mathrm{~mL})$ previously shown to improve retention under these behavioral conditions (Miyashita and Williams 2002; Kerfoot et al. 2008). The dose of phentolamine was selected from those demonstrated to be low enough not to affect memory when given alone, but sufficient to block the actions of noradrenergic agonists in previous studies (Cools et al. 1987; Roozendaal and Cools 1994).

\section{Microinjection procedure}

Rats were randomly assigned to one of four groups that received PBS into both the NAC and NTS (PBS/PBS: $n=8$ ), phentolamine in the accumbens, and PBS in the NTS (phentolamine/PBS: $n=10$ ), PBS into the accumbens and glutamate into the NTS (PBS/glutamate: $n=9$ ), or microinjections of phentolamine in the accumbens and glutamate in the NTS (phentolamine/glutamate: $n=7$ ).

\section{Retention test}

Memory for the surprising footshock in the dark compartment was assessed $24 \mathrm{~h}$ later and consisted of two phases. During Phase 1 , the rats were placed in the dark compartment facing the partially lowered metal door and given 60 sec to enter the neutral compartment or alternatively, to initiate the first lick from the water spout. If the rat entered the neutral compartment, the metal door was raised and the rat remained in the neutral compartment for 30 sec. Phase 2 of retention began after this 30-sec period. Those that did not enter the dark compartment after $60 \mathrm{sec}$ were removed and placed in the neutral compartment with the metal door raised for $30 \mathrm{sec}$. Measures recorded during Phase 1 included percentage of animals to drink from the spout, latency to drink, amount time spent drinking, and latency to escape into the neutral compartment. During Phase 2, the metal door was lowered and the time spent avoiding the dark compartment, latency to drink from the spout, total time spent drinking, and the total amount of time spent in the neutral compartment was recorded over a period of $300 \mathrm{sec}$. Figure $2 \mathrm{~A}$ and $\mathrm{B}$ depict the separate measures recorded for Phase 1and Phase 2 of the retention test, respectively.

\section{Statistical analysis}

The behavioral measures from the water-motivated inhibitory avoidance task are expressed as mean \pm standard errors (SE). Between-group comparisons for the behaviors measured during retention testing were made with a two-way ANOVA (NTS $\times$ nucleus NAC injections) followed by post hoc tests. Comparisons between the last day of training before footshock and Phase 2 of the retention test for the latency to first lick the spout from the beginning of Phase 2 and the total amount of time spent in the neutral compartment on were made with a two-way repeatedmeasures ANOVA followed by a post hoc test.

\section{Experiment 1: Histology}

Rats were deeply anesthetized with a euthanasia solution and perfused intracardially with $0.9 \%$ saline followed by $10 \%$ formalin to verify microinjection cannulae placement. The brains were stored in a $10 \%$ formalin and $12 \%$ sucrose solution until sectioned on a vibratome. Sections were cut $60 \mu \mathrm{m}$ thick, mounted on glass slides, subbed with chromium-aluminum, and stained with cresyl violet. The location of the cannulae and injection needle tips were verified by examining enlarged projections of the slides (Fig. 1A,B).

\section{Experiment 2: Microdialysis procedure}

\section{Probes}

CMA/12 (Carnegie/Medecin) dialysis probes with a 2-mm membrane tip were used to collect norepinephrine from the shell region of the NAC. The inlet arm was connected to a $1-\mathrm{mL}$ Hamilton syringe by FEP tubing, and a CMA-1000 microinfusion pump (Carnegie/Medecin) was used to drive the syringes. The outlet arm of the probe was connected by FEP tubing to $350-\mathrm{mL}$ collection vials containing $15 \mathrm{~mL}$ of dihydroxybenzylamine $(1.0 \mathrm{pg} / \mathrm{mL})$ that serves as an internal standard for HPLC analysis. The probes were perfused continuously with artificial cerebral spinal fluid (aCSF; pH 7.4; $145.0 \mathrm{mM} \mathrm{NaCl}, 4.0 \mathrm{mM} \mathrm{KCl}$, $1.2 \mathrm{mM} \mathrm{CaCl}_{2}$ and $2.0 \mathrm{mM} \mathrm{Na}_{2} \mathrm{HPO}_{4}$ ) at a flow rate of $1.0 \mathrm{~mL} /$ min. Dialysate samples of norepinephrine were collected every $20 \mathrm{~min}$ and stored on ice until assayed with HPLC.

\section{Microdialysis chamber}

Samples of dialysate were collected in a CMA/120 system roundbottomed transparent bowl with a diameter of $400 \mathrm{~mm}$ at the top designed for microdialysis experiments in conscious, freely moving animals. The system enables long-term combined studies of animal behavior and concurrent microdialysis experiments. 


\section{Microdialysis sample collection}

The microdialysis experiment consisted of five phases: habituation, baseline 1 collection, control injection, baseline 2 collection, and experimental treatment. Subjects were first transported to the laboratory and left undisturbed for $20 \mathrm{~min}$. Each rat was habituated to the chamber for $1 \mathrm{~h}$ after probe implant and no samples were collected during this time. The concentrations of norepinephrine in the first three samples collected after the habituation period were averaged to yield the baseline 1 value. Each subject was then administered an intra-NTS infusion of PBS as a control for injection, and three additional samples were collected over the next $60 \mathrm{~min}$. Afterward, two additional samples were collected, and the mean concentration of norepinephrine contained in these samples represented the baseline 2 value. Rats then received an infusion of either $50.0 \mathrm{ng} / 0.5 \mu \mathrm{L}(n=4)$ or $100.0 \mathrm{ng} / 0.5 \mathrm{~mL}(n=5)$ of l-glutamic acid into the NTS. Seven more samples were collected before the probe was removed from the guide cannula and the rat was returned to the home cage. The vials containing each sample were sealed with parafilm (Fisher Scientific) and stored on ice until assayed with HPLC.

A third group of rats was habituated to a Coulbourn behavioral chamber $\left(12^{\prime \prime} \mathrm{W} \times 10^{\prime \prime} \mathrm{D} \times 12^{\prime \prime} \mathrm{H}\right.$, Model \#: H13-16) for $17 \mathrm{~min}$ on the day prior to microdialysis collection. The front and back walls of the chamber were made of clear plastic with stainless steel sides and a removable stainless steel grid floor. On the day of microdialysis collection, animals experienced the same procedures described above. However, these animals received the lower dose of glutamate in the NTS immediately after the type of footshock that was used during training in Experiment $1 \quad(n=5$; $0.35 \mathrm{~mA}$ footshock for $2 \mathrm{sec}$ ). Animals were removed from the collection bowls and placed in the Coulbourn chamber for $1 \mathrm{~min}$ before a 2-sec, $0.35-\mathrm{mA}$ footshock was delivered. Animals remained in the chamber for an additional $60 \mathrm{sec}$ before being removed and administered NTS infusions. Following injections, animals were placed back into the CMA bowls and collection proceeded for $2 \mathrm{~h}$ and $20 \mathrm{~min}$.

It is important to note that all experimental manipulations were initiated in the final $10 \mathrm{~min}$ of the collection period that preceded the experimental treatment. This 10-min period reflects the amount of time required for the dialysate samples to be transported from the membrane of the microdialysis probe through the FEP tubing to the sample collection vials.

\section{Norepinephrine assay}

Norepinephrine concentrations in the dialysate sample were assayed by HPLC electrochemical detection (ESA). At the end of the microdialysis experiment, $35 \mu \mathrm{L}$ of each dialysate sample was loaded into a Waters 717 autosampler, automatically injected with a flow rate of $1.0 \mathrm{~mL} / \mathrm{min}$. The mobile phase consisted of $50 \mathrm{mg}$ disodium EDTA, $13.8 \mathrm{mg}$ monobasic sodium phosphate, and $58 \mathrm{mg}$ octane sulfonate adjusted to $\mathrm{pH} 3.2$ by adding $85 \%$ phosphoric acid. Norepinephrine concentrations and peak heights were measured in comparison with those of a known norepinephrine standard ( $32 \mathrm{pg} / 35 \mathrm{~mL})$. The concentration, peak height, and retention time for dialysate samples of norepinephrine were analyzed with the Millennium software package (Waters).

\section{Statistical analysis}

Unilateral sampling from the NAC was counterbalanced across hemispheres. There were no differences in basal or drug-induced fluctuations of norepinephrine concentrations between the left and right NAC. As such, the neurochemical values from both NAC were pooled together for statistical analysis. The levels (pg/ $\mathrm{mL}$ ) of norepinephrine from the three baseline samples collected before PBS injection were averaged to yield the initial baseline value of $100 \%$. The two samples obtained after the end of the PBS collection period were averaged to represent the second baseline value. The concentration of norepinephrine sampled after the PBS or glutamate injection is expressed as the percentage of change above each of these values. Comparisons between norepinephrine levels at baseline and each respective 20-min collection time points were analyzed with repeated-measures ANOVA. Factorial ANOVAs were used to assess individual differences in accumbens norepinephrine output resulting from the separate treatment conditions. Fischer's post hoc tests were used to analyze specific comparisons between treatment groups.

\section{Experiment 2: Histology}

Histological procedures were the same as those described in the previous histology section for Experiment 1 . The location of cannulae placements are displayed in Figure 5, A and B.

\section{Acknowledgments}

Research was supported by the National Science Foundation (NSF 0720170 to C.L.W.). The authors thank Elizabeth Chattillion and Amanda DiBattista for their assistance with behavioral training and histological processing of brain slices.

\section{References}

Allchin RE, Batten TFC, McWilliam PN, Vaughn PFT. 1994. Electrical stimulation of the vagus increases extracellular glutamate recovered from nucleus tractus solitarii of the cat by in vivo microdialysis. Exp Physiol 79: 265-268.

Berridge CW, Stratford TL, Foote SL, Kelley AE. 1997. Distribution of dopamine $\beta$-hydroxylase-like immunoreactive fibers within the shell subregion of the nucleus accumbens. Synapse 27: 230-241.

Bevilaqua L, Ardenghi P, Schroder N, Bromberg E, Quevedo J, Schmitz PK, Bianchin M, Walz R, Schaeffer E, Medina JH, et al. 1997. Agents that affect cAMP levels or protein kinase A activity modulate memory consolidation when injected into rat hippocampus but not amygdala. Braz J Med Biol Res 30: 967-970.

Brog JS, Salypongse A, Deutch AY, Zahm DS. 1993. The patterns of afferent innervation of the core and shell in the "accumbens" part of the rat ventral striatum: Immunohistochemical detection of retrogradely transported Fluoro-Gold. J Comp Neurol 338: 225-278.

Carvalho AF, Reyes ARS, Sterling RC, Unterwald E, Van Bockstaele EJ. 2010. Contribution of limbic norepinephrine to cannabinoid-induced aversion. Psychopharmacology 211: 479-491.

Clayton EC, Williams CL. 2000. Adrenergic activation of the nucleus tractus solitarius potentiates amygdala norepinephrine release and enhances retention performance in emotionally arousing and spatial memory tasks. Behav Brain Res 112: 151-158.

Cools AR, Ellenbroek B, van den Bos R, Gelissen M. 1987. Mesolimbic noradrenaline: Specificity, stability and dose-dependency of individual-specific responses to mesolimbic injections of a-noradrenergic agonists. Behav Brain Res 25: 49-61.

Delfs JM, Zhu Y, Druhan JP, Aston-Jones GS. 1998. Origin of noradrenergic afferents to the shell subregion of the nucleus accumbens: Anterograde and retrograde tract-tracing studies in the rat. Brain Res 806: $127-140$.

Ferry B, Roozendaal B, McGaugh JL. 1999. Role of norepinephrine in mediating stress hormone regulation of long-term memory storage: A critical involvement of the amygdala. Biol Psychiatry 46: 1140-1152.

French SJ, Totterdell S. 2003. Individual nucleus accumbens-projection neurons receive both basolateral amygdala and ventral subicular afferents in rats. Neuroscience 119: 19-31.

Fricks-Gleason AN, Marshall JF. 2008. Post-retrieval $\beta$-adrenergic receptor blockade: Effects on extinction and reconsolidation of cocaine-cue memories. Learn Mem 15: 643-648.

Groenewegen HJ, Vermeulen-Van der Zee E, te Kortschot A, Witter MP. 1987. Organization of the projection from the subiculum to the ventral striatum in the rat: A study using anterograde transport of Phaseolus vulgaris leucoagglutinin. Neuroscience 23: 103-120.

Hassert DL, Miyashita T, Williams CL. 2004. The effects of peripheral vagal nerve stimulation at a memory-modulating intensity on NE output in the basolateral amygdala. Behav Neurosci 118: 79-88.

Hatfield T, McGaugh JL. 1999. Norepinephrine infused into the basolateral amygdala posttraining enhances retention in a spatial water maze task. Neurobiol Learn Mem 71: 232-239.

Holdefer RN, Jensen RA. 1987. The effects of peripheral D-amphetamine, 4-OH amphetamine, and epinephrine on maintained discharge in the locus coeruleus with reference to the modulation of learning and memory by these substances. Brain Res 417: 108-117.

Izumi Y, Zorumski CF. 1999. Norepinephrine promotes long-term potentiation in the adult rat hippocampus in vitro. Synapse 31: 196-202. 
Kerfoot EC, Chattillion EA, Williams CL. 2008. Role of nucleus NAC neurons in processing memory for emotionally arousing events. Neurobiol Learn Mem 89: 47-60.

Khakpour-Taleghani B, Lashgari R, Motamedi F, Naghdi N. 2009. Effect of reversible inactivation of locus coeruleus on spatial reference and working memory. Neuroscience 158: 1284-1291.

King II. SOII, Williams CL. 2009. Novelty-induced arousal enhances memory for cued classical fear conditioning: Interactions between peripheral adrenergic and brainstem glutamatergic systems. Learn Mem 16: $625-634$.

Kirouac GJ, Ciriello J. 1997. Medullary inputs to nucleus accumbens neurons. Am J Physiol 273: R2080-R2088.

Kitanaka N, Kitanaka J, Watabe K, Takemura M. 2010. Low-dose pretreatment with clorgyline decreases the levels of 3-methoxy-4-hydroxyphenylglycol in the striatum and nucleus accumbens and attenuates methamphetamine-induced conditioned place preference in rats. Neuroscience 165: 1370-1376.

Kombian SB, Ananthalakshmi KV, Edafiogho IO. 2006. Enaminones and norepinephrine employ convergent mechanisms to depress excitatory synaptic transmission in the rat nucleus accumbens in vitro. Eur $J$ Neurosci 24: 2781-2788.

LaLumiere RT, Nawar EM, McGaugh JL. 2005. Modulation of memory consolidation by the basolateral amygdala or nucleus Accumbens shell requires concurrent dopamine receptor activation in both brain regions. Learn Mem 12: 296-301.

Lawrence AJ, Watkins D, Jarrott B. 1995. Visualization of $\beta$-adrenoceptor binding sites on human inferior vagal ganglia and their axonal transport along the rat vagus nerve. J Hypertens 13: 631-635.

Liang KC, Chen LL, Huang TE. 1995. The role of amygdala norepinephrine in memory formation: Involvement in the memory enhancing effect of peripheral epinephrine. Chin J Physiol 38: 81-91.

McKittrick CR, Abercrombie ED. 2007. Catecholamine mapping within nucleus accumbens: Differences in basal and amphetamine-stimulated efflux of norepinephrine and dopamine in shell and core. J Neurochem 100: $1247-1256$

Mehendale S, Xie JT, Aung HH, Guan XF, Yuan CS. 2004. Nucleus accumbens receives gastric vagal inputs. Acta Pharmacol Sin 25: $271-275$.

Meredith GE, Wouterlood FG, Pattiselanno A. 1990. Hippocampal fibers make synaptic contact with glutamate decarboxylaseimmunoreactive neurons in the rat nucleus accumbens. Brain Res 513: 329-334.

Miyashita T, Williams CL. 2002. Glutamatergic transmission in the nucleus of the solitary tract modulates memory through influences on the amygdala noradrenergic systems. Behav Neurosci 116: 13-21.

Miyashita T, Williams CL. 2004. Peripheral arousal-related hormones modulate norepinephrine release in the hippocampus via influences on brainstem nuclei. Behav Brain Res 153: 87-95.

Miyashita T, Williams CL. 2006. Epinephrine administration increases neural impulses propagated along the vagus nerve: Role of peripheral $\beta$-adrenergic receptors. Neurobiol Learn Mem 85: 116-124.

Mogenson GJ, Jones DL, Yim CY. 1980. From motivation to action: Functional interface between the limbic system and the motor system. Prog Neurobiol 14: 69-97.

Nicola SM, Malenka RC. 1998. Modulation of synaptic transmission by dopamine and norepinephrine in ventral but not dorsal striatum. I Neurophysiol 79: 1768-1776.

Nicola SM, Kombian SB, Malenka RC. 1996. Psychostimulants depress excitatory synaptic transmission in the nucleus accumbens via presynaptic D1-like dopamine receptors. J Neurosci 16: 1591-1604.

Nurse B, Russell VA, Taljaard JJ. 1984. $\alpha 2$ and $\beta$-adrenoceptor agonists modulate $[3 \mathrm{H}]$ dopamine release from rat nucleus accumbens slices: Implications for research into depression. Neurochem Res 9: $1231-1238$.

Park J, Aragona BJ, Kile BM, Carelli RM, Wightman RM. 2010. In vivo voltammetric monitoring of catecholamine release in sub-territories of the nucleus accumbens. Neuroscience 169: 132-142.

Paxinos G, Watson C. 1986. The rat brain in stereotaxic coordinates. Academic Press, Sydney.

Petrovich GD, Risold PY, Swanson LW. 1996. Organization of projections from the basomedial nucleus of the amygdala: A PHAL study in the rat. J Comp Neurol 347: 387-420.

Radwanska K, Nikolaev E, Kaczmarek L. 2010. Central noradrenergic lesion induced by DSP-4 impairs the acquisition of avoidance reactions and prevents molecular changes in the amygdala. Neurobiol Learn Mem 94: $303-311$.

Rainbow TC, Parsons B, Wolfe BB. 1984. Quantitative autoradiography of $\beta 1$ and $\beta 2$-adrenergic receptors in rat brain. Proc Natl Acad Sci 81: $1585-1589$.

Reisine TD, Chesselet MF, Lubetzki C, Cheramy A, Glowinski J. 1982. A role for striatal $\beta$-adrenergic receptors in the regulation of dopamine release. Brain Res 24: 123-130.

Roosevelt RW, Smith DC, Clough RW, Jensen RA, Browning RA. 2006. Increased extracellular concentrations of norepinephrine in cortex and hippocampus following vagus nerve stimulation in the rat. Brain Res 1119: $124-132$.

Roozendaal B, Cools AR. 1994. Influence of the noradrenergic state of the nucleus accumbens in basolateral amygdala mediated changes in neophobia of rats. Behav Neurosci 108: 1107-1118.

Roozendaal B, Castello NA, Vedana G, Barsegyan A, McGaugh JL. 2008. Noradrenergic activation of the basolateral amygdala modulates consolidation of object recognition memory. Neurobiol Learn Mem 90: $576-579$.

Schroeter S, Apparsundaram S, Wiley RG, Miner LH, Sesack SR, Blakely RD. 2000. Immunolocalization of the cocaine- and antidepressant-sensitive l-norepinephrine transporter. J Comp Neurol 420: 211-232.

Scullion GA, Kendall DA, Sunter D, Marsden CA, Pardon MC. 2009. Central noradrenergic depletion by DSP-4 prevents stress-induced memory impairments in the object recognition task. Neuroscience 164: $415-423$.

Segal M, Markram H, Richter-Levin G. 1991. Actions of norepinephrine in the rat hippocampus. Prog Brain Res 88: 323-330.

Tuinstra T, Cools AR. 2000. Newly synthesized dopamine in the nucleus accumbens is regulated by $\beta$-adrenergic, but not $\alpha$-adrenergic, receptors. Neuroscience 98: 743-747.

Unnerstall JR, Kopajtic RA, Kuhar MJ. 1984. Distribution of $\alpha 2$ agonist binding sites in the rat and human central nervous system: Analysis of some functional, anatomic correlates of the pharmacologic effects of clonidine and related adrenergic agents. Brain Res 319: 69-101.

Wang ZJ, Rao ZR, Shi JW. 1992. Tyrosine hydroxylase-, neurotensin-, or cholecystokinin-containing neurons in the nucleus tractus solitarii send projection fibers to the nucleus accumbens in the rat. Brain Res 578: $347-350$.

Williams CL, Men D, Clayton EC, Gold PE. 1998. Norepinephrine release in the amygdala after systemic injection of epinephrine or escapable footshock: Contribution of the nucleus of the solitary tract. Behav Neurosci 112: 1414-1422.

Williams CL, Men D, Clayton EC. 2000. The effects of noradrenergic activation of the nucleus tractus solitarius on memory and in potentiating norepinephrine release in the amygdala. Behav Neurosci 114: $1131-1144$.

Received December 8, 2010; accepted in revised form March 31, 2011. 


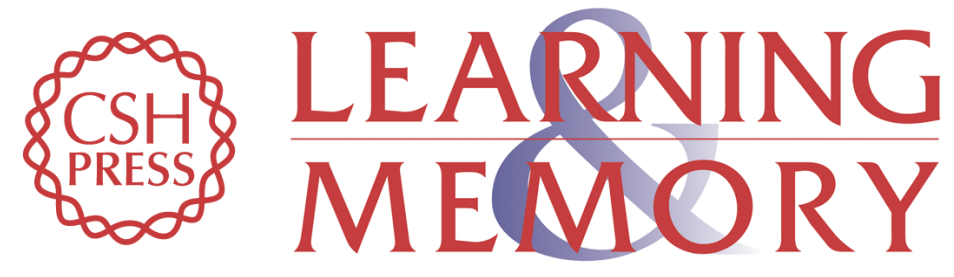

\section{Interactions between brainstem noradrenergic neurons and the nucleus accumbens shell in modulating memory for emotionally arousing events}

Erin C. Kerfoot and Cedric L. Williams

Learn. Mem. 2011, 18:

Access the most recent version at doi:10.1101//m.2108911

References This article cites 51 articles, 5 of which can be accessed free at: http://learnmem.cshlp.org/content/18/6/405.full.html\#ref-list-1

License

Email Alerting Receive free email alerts when new articles cite this article - sign up in the box at the Service top right corner of the article or click here. 